\title{
Kinetic and thermodynamic investigations of strontium ions retention by natural kaolinite and clinoptilolite minerals
}

\author{
By D. Akar, T. Shahwan* and A. E. Eroglu \\ Department of Chemistry, Faculty of Science, Izmir Institute of Technology, 35430 Urla, Izmir, Turkey
}

(Received March 14, 2005; accepted in revised form May 27, 2005)

\section{$\mathrm{Sr}^{2+} /$ Sorption / Kaolinite / Clinoptilolite}

Summary. The current study was devoted to the determination of various thermodynamic and kinetic parameters resulting from the fixation of $\mathrm{Sr}^{2+}$ by natural samples of kaolinite and clinoptilolite minerals. The sorption process followed pseudo second order kinetics, with faster sorption on kaolinite compared to clinoptilolite, where the uptake is affected by intraparticle diffusion. Freundlich and Dubinin-Radushkevich isotherm models described the data more adequately than Langmuir model, and clinoptilolite showed a higher strontium sorption capacity than kaolinite. Thermodynamically, the activation energy of $\mathrm{Sr}^{2+}$ sorption by kaolinite and clinoptilolite were respectively, -8.5 and $-18.4 \mathrm{~kJ} / \mathrm{mol}$. The sorption process on both minerals was spontaneous and endothermic at all the studied concentrations, with $\Delta H^{\circ}$ being 11.3 and $9.8 \mathrm{~kJ} / \mathrm{mol}$, for sorption on kaolinite and clinoptilolite, respectively. The findings of this study were compared with those of an earlier study on the uptake of $\mathrm{Cs}^{+}$by the same minerals.

\section{Introduction}

In this study, some kinetic and thermodynamic aspects of the sorption of $\mathrm{Sr}^{2+}$ by natural kaolinite and clinoptilolite were studied. The results were compared with those of an earlier study in which the same parameters were investigated for $\mathrm{Cs}^{+}$sorption on the same minerals [1].

Strontium, $\mathrm{Sr}$, is an alkali-earth element found in rocks, soil, coal, and oil. This element has four stable isotopes $\left({ }^{84} \mathrm{Sr},{ }^{86} \mathrm{Sr},{ }^{87} \mathrm{Sr},{ }^{88} \mathrm{Sr}\right)$ and more than twenty radioactive isotopes possessing variable half-lives [2]. In addition to the possibility of contaminating soil, $\mathrm{Sr}$ is soluble in water and can travel deeper to the underground water, thus posing the risk of contaminating its natural resources and consequently entering the food chain. Among Sr compounds, strontium chromate is considered to be the most dangerous to human health. Due to its long half-life and its high yield in fission reactions, ${ }^{90} \mathrm{Sr}\left(t_{1 / 2}=29.1\right.$ years $)$ is considered to be among the most important isotopes from the view point of radioactive waste management. This radioisotope is also generated commercially for uses in medicine and industry.

Kaolinite and clinoptilolite are two different types of aluminosilicates, a family of soil components widely present in

\footnotetext{
*Author for correspondence (E-mail: talalshahwan@iyte.edu.tr).
}

the crust of Earth. The former is a clay mineral consisting of a non-expandable layered structure, with sorption sites located mainly on the outer surface and edge parts of its matrix. The latter is the most predominant form of zeolites, which have a cage structure and consequently possess internal surfaces accessible to only ions and molecules under a certain size.

Different aspects of the sorption behavior of $\mathrm{Sr}^{2+}$ on kaolinite and clinoptilolite were investigated previously by many authors [e.g. 3-15]. Although these studies have provided valuable information about various macroscopic and microscopic aspects of the fixation behavior of this ion, only a limited area was devoted to reveal the kinetic and thermodynamic characteristics of the sorption process. According to our literature survey, loading, $\mathrm{pH}$, organic coatings, and ionic strength were the most extensively studied parameters, in addition to a limited number of works that dealt with the sorption of $\mathrm{Sr}^{2+}$ on kaolinite and clinoptilolite from a mechanistic microscopic perspective.

In a study of $\mathrm{Cs}$ and $\mathrm{Sr}$ uptake to kaolinite weathering in simulated tank waste leachate, it was reported that the Sr sorption was rapid and substantial and was described using first order kinetics [3]. In another study, the removal of ${ }^{90} \mathrm{Sr}$ by kaolinite was reported to greatly increase as the concentration of groundwater cations increased and that the $\mathrm{pH}$ exerted a small effect on the retardation of ${ }^{90} \mathrm{Sr}$ onto kaolinite [4]. On the contrary, another work indicated that the sorption of $\mathrm{Sr}^{2+}$ showed an increase with the increased $\mathrm{pH}$. The same study revealed that the presence of humic acids at high concentrations and $\mathrm{pH}>5$ reduced the amount of sorbed ${ }^{90} \mathrm{Sr}$ ions [5]. Another work have also estimated that the organic-inorganic complex made up of kaolinite particles coated with humic substances, plays an important role in the behavior of various ions (including $\mathrm{Sr}^{2+}$ ) in the environment [6]. In a study to reveal the effect of loading on the sorption of strontium by kaolinite, it was stated that the fraction of this element retained on the solids increased with decreasing radio-element $\left({ }^{90} \mathrm{Sr}\right)$ concentration and that the sorption data were fitted to the Freundlich isotherm model [7]. Microscopically, quantitative analyses of Sr-loaded kaolinite samples using EXAFS showed a single first shell of 9-10 $( \pm 1)$ oxygen atoms surrounding sorbed strontium at an average $\mathrm{Sr}-\mathrm{O}$ bond-distance of $2.61( \pm 0.02) \AA$, indicating hydrated surface complexes [8]. A different study reported, based on EXAFS findings, that at 
low initial $\mathrm{Sr}^{2+}$ concentrations this ion was taken up as a partially aquated species into octahedral sites on the kaolinite surface [9]. According to the same study, at higher concentrations, longer average $\mathrm{Sr}-\mathrm{O}$ bond distances were observed suggesting weaker binding of $\mathrm{Sr}^{2+}$ to the kaolinite surface. In line with this, and based on characterization using XAS, it was suggested that sorbed $\mathrm{Sr}$ is weakly bonded to clay surfaces, regardless of solution conditions and adsorbent and that sorption involved formation of mononuclear outersphere complexes of Sr at clay-water interfaces [10].

Strong sorption abilities of clinoptilolite fractions toward $\mathrm{Sr}^{2+}$ were documented in a number of studies [11-13]. The sorption uptake of Sr was observed to increase with decreasing ionic strength of background solution and desorption of this ion from a sample of zeolitic tuffs, containing clinoptilolite, was reported to be enhanced by increased background electrolyte concentration [11]. The same study reported that the fixation of $\mathrm{Sr}^{2+}$ by clinoptilolite occurs via ion-exchange in addition to outer sphere complex formation, with the latter being $\mathrm{pH}$ dependent. The efficiency of clinoptilolite in removing ${ }^{90} \mathrm{Sr}$ from liquid radioactive wastes was reported, and an optimum operational $\mathrm{pH}$ of 8 was suggested [12]. The strong sorption characteristics of clinoptilolite towards $\mathrm{Sr}^{2+}$ were also confirmed by another study which examined effects of particle size, water-to-rock ratios, $\mathrm{pH}$ values of simulated groundwater and concentration of $\mathrm{Sr}^{2+}$ in the simulated groundwater on the distribution ratios, $R_{\mathrm{d}}$, of $\mathrm{Sr}^{2+}$ ions [13]. Due to its prominent sorption capacity towards radioactive strontium retention, clinoptilolite was reported to possess a potential use as countermeasure amendments in radiostrontium contaminated soils [14], or as a backfill in potential nuclear waste repositories [15].

In this study, the primary parameters investigated include the time of contact, concentration, temperature, in addition to desorption. These studies aim at elucidating information regarding the kinetics of sorption, including the rate constants and activation energies, the best fitting sorption isotherm models, and the thermodynamic parameters, $\Delta H^{\circ}$, $\Delta S^{\circ}$ and $\Delta G^{\circ}$ of sorption. The desorption behavior of $\mathrm{Sr}^{2+}$ was tested to reveal the stability of fixation and the structural and morphological stability of kaolinite and clinoptilolite upon sorption was examined.

\section{Experimental}

Kaolinite and clinoptilolite applied in this work were natural minerals obtained from Sindirgi and Manisa regions situated in the western part of Anatolia. Dry sieving of the samples showed that the particle size of kaolinite used in this study was $<38 \mu \mathrm{m}$ while that of clinoptilolite was $75-150 \mu \mathrm{m}$. The natural samples of kaolinite and clinoptilolite were characterized for their BET and Langmuir surface areas by means of a Micrometrics ASAP 2010 instrument using nitrogen at $77 \mathrm{~K}$. The analyzed samples were degassed for 3 hours at $353 \mathrm{~K}$. The results showed that BET and Langmuir surface area for kaolinite are, respectively, 6.9 and $9.7 \mathrm{~m}^{2} / \mathrm{g}$. The same analysis for clinoptilolite gave values of 31.7 and $45.2 \mathrm{~m}^{2} / \mathrm{g}$, respectively. The average pore diameter $(4 \mathrm{~V} / \mathrm{A}$ by BET) of clinoptilolite was determined to be $61.3 \AA$.
XRPD analysis of the mineral phases was performed using a Philips X'Pert Pro diffractometer. The samples were first ground, mounted on silicon holders then introduced for analysis. The source consisted of $\mathrm{Cu} K_{\alpha}$ radiation $(\lambda=$ $1.54 \AA)$. Each sample was scanned within the 2 theta range of 2-60. The results indicated that natural kaolinite contained quartz as the major impurity in addition to a minor amount of smectite-type clay. On the other hand, the XRPD diagram of clinoptilolite indicated that the mineral was almost pure.

The SEM/EDS characterization was carried out using a Philips XL-30S FEG type instrument Prior to analysis; the solid samples were sprinkled onto adhesive carbon tapes supported on metallic disks. Images of the sample surfaces were then recorded at different magnifications. EDS elemental analysis was performed at different points on the surface in order to minimize any possible anomalies arising from the heterogeneous nature of the analyzed surface. The results of SEM analysis showed that kaolinite has a well-defined crystal structure as seen from the characteristic hexagonal morphology with edge sizes ranging from 300-500 nm as given in Fig. 1a. Clinoptilolite, however, seemed to be composed of crystals with characteristic

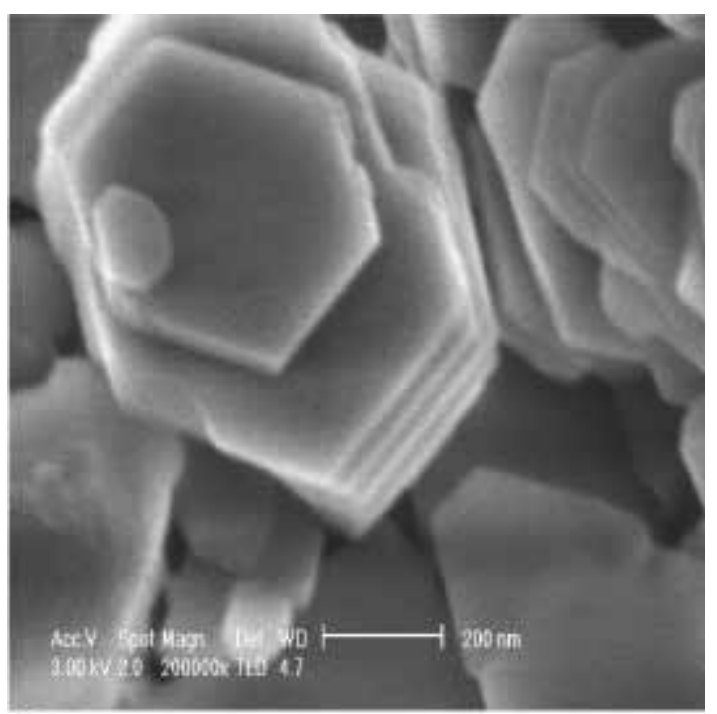

(a)

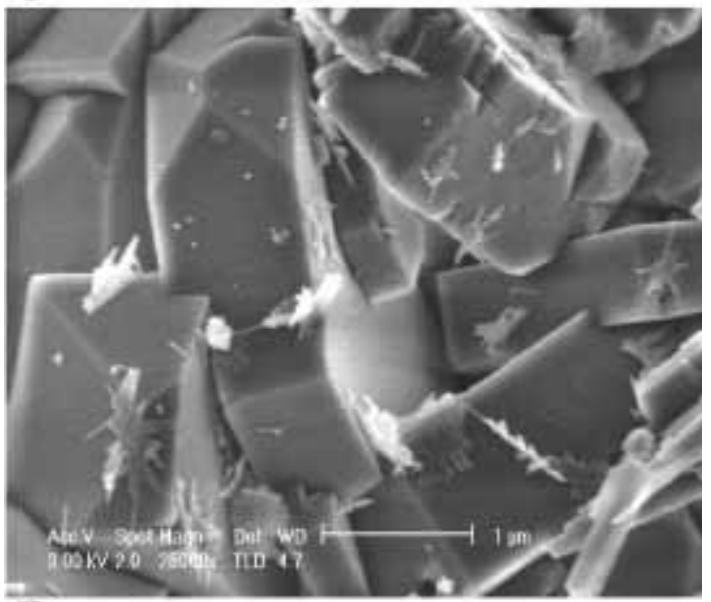

b

Fig. 1. Typical SEM micrographs of (a) kaolinite, and (b) clinoptilolite. 
coffin-like shape and size that amounts to several micrometers as shown by Fig. 1b. The EDS results showed that the average elemental content of kaolinite was $66.8 \% \mathrm{O}, 17.6 \%$ $\mathrm{Si}, 14.1 \% \mathrm{Al}$ in addition to minor quantities of $\mathrm{Na}, \mathrm{K}, \mathrm{Mg}$, and $\mathrm{Ca}$ probably originating from the other impurities that could not be detected by XRPD. The average elemental content of clinoptilolite obtained by EDS was 61.9\% O, 23.7\% $\mathrm{Si}, 5.3 \% \mathrm{Al}$, including small amounts of $\mathrm{Na}, \mathrm{K}, \mathrm{Mg}$, and $\mathrm{Ca}$. The numbers represent the arithmetic average of five data points obtained from random locations on the mineral surface. Prior to the sorption experiments, the mineral samples were equilibrated with tapwater. This pretreatment step aimed to mimic the equilibrium situation of the minerals with groundwater. AAS analysis of tapwater showed that the concentrations of $\mathrm{Na}^{+}, \mathrm{K}^{+}, \mathrm{Mg}^{2+}$, and $\mathrm{Ca}^{2+}$ were $18,3,26$, and $200 \mathrm{mg} / \mathrm{L}$, respectively. In each batch of the pretreatment experiments, $10.0 \mathrm{~g}$ of the mineral and $1000 \mathrm{~mL}$ of laboratory tapwater were mixed on a lateral shaker at room temperature for 4 days. The mineral samples were then filtered and dried in an oven kept at $90^{\circ} \mathrm{C}$ for 12 hours.

The sorption experiments were carried out using 50-ml polyethylene tubes. The tubes were first cleaned, dried, and weighed. To each tube, $0.50 \mathrm{~g}$ of kaolinite or clinoptilolite samples were added, followed by the addition of $50.0 \mathrm{ml}$ of aqueous $\operatorname{Sr}\left(\mathrm{NO}_{3}\right)_{2}$ solution. The solutions of $\operatorname{Sr}\left(\mathrm{NO}_{3}\right)_{2}$ were prepared using tapwater at the initial concentrations of 10 , 50,100 and $500 \mathrm{mg} / \mathrm{L}$. The mixtures were then mixed using a Nuve ST 402 water bath shaker equipped with a microprocessor thermostat. The experiments were carried out at $25^{\circ} \mathrm{C}$ and $60^{\circ} \mathrm{C}$ for contact periods of $5 \mathrm{~min}, 10 \mathrm{~min}, 30 \mathrm{~min}$, 1 hour, 2 hours, 5 hours, 8 hours, 24 hours, and 48 hours. At the end of each mixing period, the samples were filtered and dried. The filtrate was then analyzed using flame AAS using a Thermal Elemental SOLAAR M6 Series-type instrument with a $\operatorname{Sr} \operatorname{lamp}(\lambda=460.7 \mathrm{~nm})$ applied as a source. In all experiments, the $\mathrm{pH}$ ranged between 6.2-7.7, which is above the zero point of charge (ZPC) for both minerals, thus guaranteeing that the minerals were negatively charged during the sorption experiments.

In the desorption experiments, samples of Sr-loaded kaolinite and Sr-loaded clinoptilolite, prepared previously after 48 hours of mixing, were exposed to tapwater and shaken for a time period that lasted for one week. Analysis of the eluted $\mathrm{Sr}$ were performed at $10 \mathrm{~min}, 4$ hours, 24 hours, and 7 days. The concentration of the eluted Sr was then measured using AAS.

\section{Results and discussion}

\section{I - Kinetic of sorption}

The kinetic studies of sorption on kaolinite and clinoptilolite minerals were carried out for different initial concentrations of $10,50,100$, and $500 \mathrm{mg} / \mathrm{L} \operatorname{Sr}\left(\mathrm{NO}_{3}\right)_{2}$ at $25^{\circ} \mathrm{C}$ and $60^{\circ} \mathrm{C}$. The variation of the sorbed amounts of $\mathrm{Sr}^{2+}$ on kaolinite and clinoptilolite at a temperature of $25^{\circ} \mathrm{C}$ is provided in Figs. 2a,b, respectively. Apart from the sorbed quantities, similar trends were observed in the experiments carried out at $60^{\circ} \mathrm{C}$. The sorption of $\mathrm{Sr}^{2+}$ on kaolinite, in particular at highest loadings, passes initially through a step of fast accumulation of ions at the surface of kaolinite followed by a par-
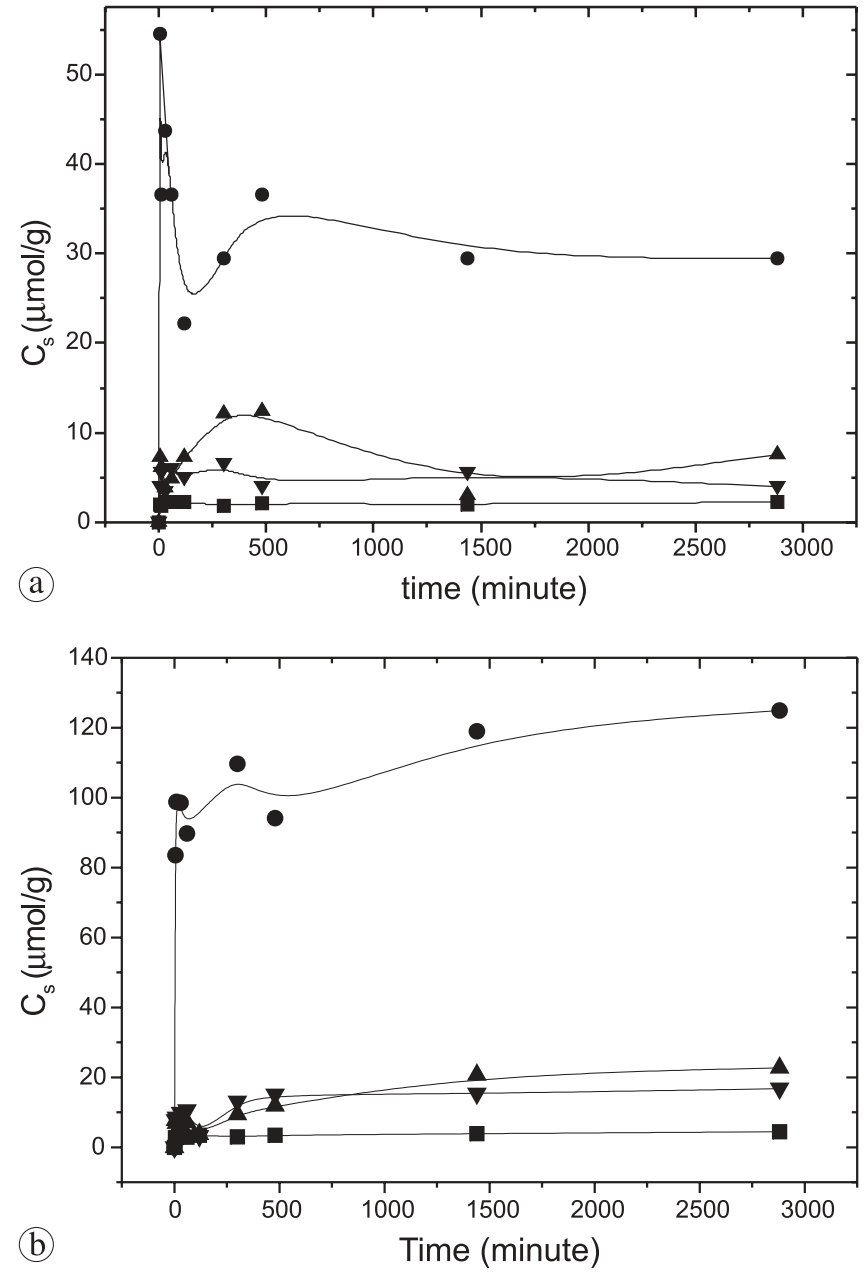

Fig. 2. Variation of the sorbed amount of $\mathrm{Sr}^{2+}(\mu \mathrm{mol} / \mathrm{g})$ with time at $25^{\circ} \mathrm{C}$ on (a) kaolinite, and (b) clinoptilolite. $\square: 10 \mathrm{mg} / \mathrm{L}, \bullet: 50 \mathrm{mg} / \mathrm{L}$, •: $100 \mathrm{mg} / \mathrm{L}$, : $500 \mathrm{mg} / \mathrm{L}$.

tial desorption that leads to attainment of equilibrium. This behavior is similar to the one reported earlier for $\mathrm{Cs}^{+}[1]$, which could be indicating that such a trend stems from the sorption characteristics of the clay. As was reported for $\mathrm{Cs}^{+}$, the extent of fixation of $\mathrm{Sr}^{2+}$ by clinoptilolite at the highest studied loading is showing a progressive increase leading to equilibrium attainment within the second day of contact. As seen from the figures, smaller periods of contact would be enough to reach equilibrium when loading is decreased.

The kinetic data was used in the determination of the rate constants and activation energies of sorption. In order to calculate the "apparent" rate constant, the following pseudo second order equation was used [16]:

$$
\frac{t}{[C]_{\mathrm{s}}}=\left(\frac{1}{k_{2}[C]_{\mathrm{e}}^{2}}\right)+\left(\frac{1}{[C]_{\mathrm{e}}}\right) t
$$

where $[C]_{\mathrm{S}}$ is the concentration of sorbed ion on the solid at time $t(\mu \mathrm{mol} / \mathrm{g}),[C]_{\mathrm{e}}$ is the concentration of sorbed ion at equilibrium, and $k_{2}$ is the pseudo pseudo second order rate constant $\mu \mathrm{g} / \mu \mathrm{mol} \mathrm{min}$ ), respectively. In the above equations, $[C]_{\mathrm{s}}$ was calculated using the following equation:

$$
[C]_{\mathrm{s}}=\left([C]_{0}-[C]_{1}\right) \frac{V}{M},
$$


Table 1. The values of $k_{2},[C]_{\mathrm{e}}$, and $E_{\mathrm{a}}$ obtained from the linear fits of the experimental data corresponding to $\mathrm{Sr}^{2+}$ sorption on kaolinite and clinoptilolite to the second order rate equation. $R$ is the linear correlation coefficient.

\begin{tabular}{lccccc}
\hline Sample & $\begin{array}{c}\text { Temperature } \\
\left({ }^{\circ} \mathrm{C}\right)\end{array}$ & $\begin{array}{c}{[C]_{\mathrm{e}}} \\
(\mu \mathrm{mol} / \mathrm{g})\end{array}$ & $\begin{array}{c}k_{2} \\
(\mathrm{~g} / \mu \mathrm{molmin})\end{array}$ & $R$ & $\begin{array}{c}E_{\mathrm{a}} \\
(\mathrm{kJ} / \mathrm{mol})\end{array}$ \\
\hline Sr-loaded kaolinite & 25 & 29 & $3.6 \times 10^{-4}$ & 0.9994 & -8.5 \\
& 60 & 68 & $2.5 \times 10^{-4}$ & 0.9836 & \\
\hline Sr-loaded clinoptilolite & 25 & 125 & $3.3 \times 10^{-4}$ & 0.9981 & -18.4 \\
& 60 & 148 & $1.5 \times 10^{-4}$ & 0.9994 & \\
\hline
\end{tabular}

where $[C]_{0}$ is the initial concentration of $\mathrm{Sr}^{2+}(\mu \mathrm{mol} / \mathrm{L})$, $[C]_{1}$ is the equilibrium concentration of $\mathrm{Sr}^{2+}$ in solution $(\mu \mathrm{mol} / \mathrm{L}), V$ is the volume of the solution $(\mathrm{L})$, and $M$ is the mass of the solid (g). Eq. (1) was adequately followed by the sorption data of $\mathrm{Sr}^{2+}$ on kaolinite and clinoptilolite. The plots using second order kinetics of $\mathrm{Sr}^{2+}$ sorption on kaolinite and clinoptilolite are given in Figs. 3a,b for sorption at temperatures of $25^{\circ} \mathrm{C}$ and $60{ }^{\circ} \mathrm{C}$ corresponding to initial $\operatorname{Sr}\left(\mathrm{NO}_{3}\right)_{2}$ concentration of $500 \mathrm{mg} / \mathrm{L}$. Eq. (1) was applied at this initial concentration only because at lower concentrations the attainment of equilibrium was so rapid that the uptake by the solids showed no variation with time. The constants $[C]_{\mathrm{e}}$ (equilibrium coverage) and $k_{2}$ (apparent rate constant) were obtained from the slope and intercept of the plots of $t /[C]_{\mathrm{s}}$ against $t$. The values of these constants are given in Table 1 . As seen from the table, the $k_{2}$ values indicate that the sorption


Fig. 3. Pseudo second order fits for the kinetic data corresponding to $\mathrm{Sr}^{2+}$ sorption on (a) kaolinite, (b) clinoptilolite. $\mathbf{~ \square : ~} 298 \mathrm{~K}$, ๑: $333 \mathrm{~K}$. of $\mathrm{Sr}^{2+}$ by kaolinite is faster than that of clinoptilolite, possibly indicating that the sorption sites on the former mineral is more easily accessible than those on the latter.

The activation energy of sorption $\left(E_{\mathrm{a}}, \mathrm{kJ} / \mathrm{mol}\right)$ can be calculated using the following equation:

$$
\ln \frac{k_{2}\left(T_{2}\right)}{k_{2}\left(T_{1}\right)}=-\frac{E_{\mathrm{a}}}{R}\left(\frac{1}{T_{2}}-\frac{1}{T_{1}}\right) \text {. }
$$

Here, $R$ is the perfect gas constant $(8.3145 \mathrm{~J} / \mathrm{mol} \mathrm{K}), k_{2}\left(T_{1}\right)$ and $k_{2}\left(T_{2}\right)$ are, respectively, the rate constants at two different temperatures. The activation energy provides a measure of the energetic barrier that the $\mathrm{Sr}^{2+}$ ions have to overcome prior to being fixed by the sorption sites. The calculated values of $E_{\mathrm{a}}(\mathrm{kJ} / \mathrm{mol})$ which are given in Table 1 came out to be negative due to the decrease in the value of the rate constants upon increase in temperature. As can be seen, the absolute $E_{\mathrm{a}}$ value corresponding to sorption of $\mathrm{Sr}^{2+}$ on kaolinite is smaller than the one related with fixation on clinoptilolite, indicating that the energetic barrier against sorption on kaolinite is easier to overcome when compared with that on clinoptilolite. This is possibly resulting from the sorption sites of kaolinite being mainly present on the external surface and edge locations which are more easily accessible. That is, it would be enough for $\mathrm{Sr}^{2+}$ ions to reach the boundary sorption layer (the solid-liquid interface) to overcome the film diffusion barrier on kaolinite, and finally undergo the exchange reaction that leads to fixation on the sorption sites. In the case of clinoptilolite, in addition to surface sites, there are sorption sites inside the channels of the mineral. Consequently, it is necessary for part of $\mathrm{Sr}^{2+}$ ions, at least, to additionally overcome the pore diffusion barrier before reaching the internal sorption sites and undergoing the intrinsic exchange reaction.

Based on the kinetic data, the effect of intraparticle (pore) diffusion on sorption was tested using the following equation [17]:

$$
[C]_{\mathrm{s}}=k_{\mathrm{p}} t^{1 / 2}+C,
$$

where $k_{\mathrm{p}}$ is the intraparticle diffusion rate constant $(\mathrm{g} / \mu \mathrm{mol} \min )$ and $C$ is a constant related to the boundary layer thickness. This equation is useful in revealing whether particle diffusion is effective in the course of the sorption process, and thus allows for a comparison of particle diffusion with film diffusion.

The plots of the sorption data of $\mathrm{Sr}^{2+}$ on kaolinite revealed that no linear behavior was observed over the studied time range. A typical plot corresponding is shown in Fig. 4a This is indicative that intraparticle diffusion has no role to play in the sorption case of kaolinite. This seems to be inline with the fact that the sorption sites on kaolinite are situated at the outer surface of the clay, which possesses a tight in- 

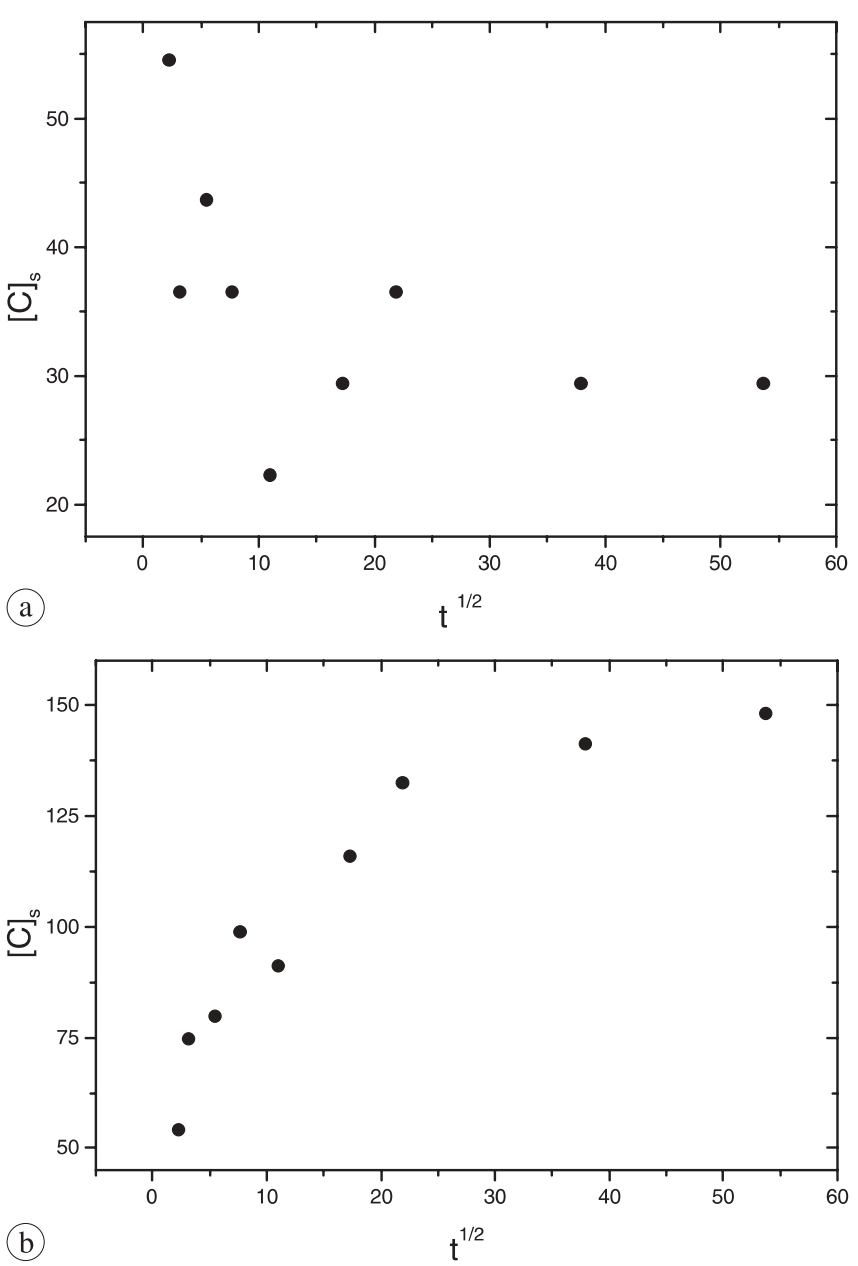

Fig. 4. The Intra-particle diffusion plots of sorbed $\mathrm{Sr}^{2+}$ on (a) kaolinite, and (b) clinoptilolite.

terlayer structure that greatly hinders the diffusion of sorbate ions within the lattice of the clay. Thus, it might be argued that film diffusion is the main resistance against sorption on kaolinite. However, in light of the observations reported earlier and shown in Fig. 2a, it is possible to conclude that the fast accumulation of ions followed by partial desorption that lead to equilibrium, means that the exchange reaction (intrinsic sorption) on kaolinite sites is slower than the transfer rate of $\mathrm{Sr}^{2+}$ ions from the bulk of the solutions to the boundary layer. This is possibly due to the competition between the sorbate ions towards the limited number of sorption sites on kaolinite.

On the other hand, the kinetic data of $\mathrm{Sr}^{2+}$ sorption on clinoptilolite plotted using Eq. (4) showed a linear behavior at the initial stages of sorption (time $<\sim 400$ minutes) followed by a plateau as shown in Fig. 4b. This suggests that the intraparticle diffusion (diffusion of $\mathrm{Sr}^{2+}$ into the pores of clinoptilolite) affects the initial uptake steps of $\mathrm{Sr}^{2+}$ by clinoptilolite, but it is not the rate determining step [17]. The values of $k_{\mathrm{p}}$ obtained from the linear portion in Fig. $4 \mathrm{~b}$ were 1.54 and $3.79 \mathrm{~g} / \mu \mathrm{mol}$ min for $\mathrm{Sr}^{2+}$ sorption on clinoptilolite at $25^{\circ} \mathrm{C}$ and $60^{\circ} \mathrm{C}$, respectively. Based on these results it might be concluded that although intraparticle diffusion is important, film diffusion (mass transport of $\mathrm{Sr}^{2+}$ ions across the boundary layer) is kinetically slower and thus contributes seriously to the barriers standing against sorption of $\mathrm{Sr}^{2+}$ on clinoptilolite.

\section{II - Sorption isotherm models}

Sorption isotherms are mathematical models that describes the distribution of the sorbate specie among liquid and solid phases, based on a set of assumptions that are mainly related to the heterogeneity/homogeneity of the solid surface, the type of coverage, and the possibility of interaction between the sorbate specie. The sorption data of $\mathrm{Sr}^{2+}$ ions on kaolinite and clinoptilolite were examined using three types of the most widely used isotherms; Langmuir isotherm model, Freundlich isotherm model, and Dubinin-Radushkevich isotherm model. The results indicated that Freundlich and Dubinin-Radushkevich (D-R) isotherm models described better the sorption data compared to Langmuir isotherm model. Freundlich and D-R models are adequate for sorption on heterogeneous surfaces, and allows for any plausible interactions between the sorbed specie, but while Freundlich isotherm does not predict any sorption capacity, i.e., no limitation on the extent of multiplayer sorption, D-R isotherm defines a maximum sorption capacity for the fixed sorbates. Freundlich Isotherm is given by the equation:

$$
[C]_{\mathrm{s}}=k[C]_{1}^{n} .
$$

The value of Freundlich constant, $k$, can be correlated with the capacity of a particular solid towards sorption under the particular experimental conditions. However, since Freundlich isotherm does not predict a maximum coverage for a given sorbent, it is hard to consider that $k$ corresponds to the maximum sorption capacity. The value of $k$ can, nevertheless, be useful in providing a qualitative comparison for the fixation ability (affinity) of a given sorbent towards different sorbates. The other Fruendlich constant, $n$, can have the value of unity (linear sorption), the thing rarely observed when natural geological samples are used, or it can be smaller or larger than unity, with the latter case also rarely observed. The closer the value of $n$ to unity implies that no significant decrease in the fixation capacity of the surface occurs upon increasing the initial concentration of the sorbate. The linear fits of the sorption data of $\mathrm{Sr}^{2+}$ on kaolinite and clinoptilolite at $25^{\circ} \mathrm{C}$ and $60{ }^{\circ} \mathrm{C}$ are given in Fig. 5 . The values of the Freundlich constants obtained from these plots are also provided in Table 2. According to the $n$ values, the sorption of $\mathrm{Sr}^{2+}$ on both minerals is showing a moderate nonlinearity. On the other hand, the magnitude of $k$ values indicates that clinoptilolite has a higher sorption affinity towards $\mathrm{Sr}^{2+}$.compared with kaolinite. The increase in temperature appears to increase the values of both of Freundlich constants.

Table 2. Freundlich parameters, $n$ and $k$, obtained from the plots of $\mathrm{Sr}^{2+}$ uptake by kaolinite and clinoptilolite at $25^{\circ} \mathrm{C}$ and $60^{\circ} \mathrm{C}$.

\begin{tabular}{lccrc}
\hline \multirow{2}{*}{ Sample } & Temperature & \multicolumn{3}{c}{ Freundlich constants } \\
\cline { 3 - 5 } & $\left({ }^{\circ} \mathrm{C}\right)$ & $n$ & $k$ & $R$ \\
\hline Sr-kaolinite & 25 & 0.58 & 1 & 0.9594 \\
& 60 & 0.69 & 4 & 0.8877 \\
\hline Sr-clinoptilolite & 25 & 0.53 & 4 & 0.9599 \\
& 60 & 0.60 & 10 & 0.9836 \\
\hline
\end{tabular}



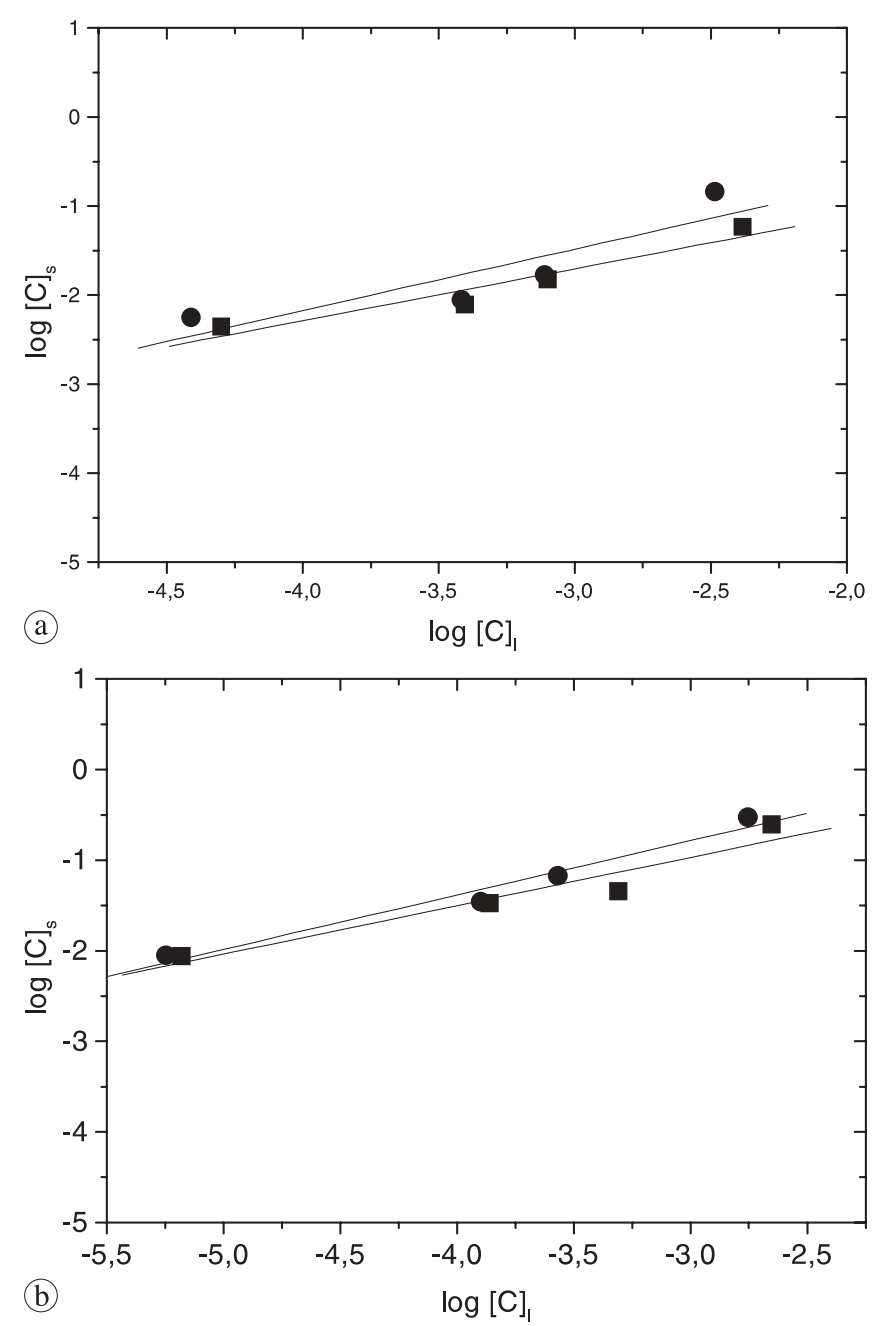

Fig. 5. Freundlich isotherm model plots of $\mathrm{Sr}^{2+}$ sorbed by (a) kaolinite, and (b) by clinoptilolite. $\mathbf{\square}: 298 \mathrm{~K}$, $: 333 \mathrm{~K}$.

$\mathrm{D}-\mathrm{R}$ isotherm model is described by the equation:

$$
[C]_{\mathrm{s}}=C_{\mathrm{m}} \exp \left(-K \varepsilon^{2}\right) .
$$

The magnitude of D-R parameter $C_{\mathrm{m}}$ corresponds to the sorption monolayer capacity and $K$ gives information about sorption energy $E$. The values of $C_{\mathrm{m}}$ and $K$ are evaluated from the intercepts and slopes of plot of $\ln [C]_{\mathrm{s}} v s . \varepsilon^{2}$. The $\mathrm{D}-\mathrm{R}$ plots corresponding to sorption of $\mathrm{Sr}^{2+}$ on kaolinite and clinoptilolite for the contact time of 48 hours and temperatures of $25^{\circ} \mathrm{C}$ and $60^{\circ} \mathrm{C}$ are given in Fig. 6. The values of D-R constants are also presented in Table 3 . According to $\mathrm{Cm}$ values, the sorption capacity of clinoptilolite is bigger than that of kaolinite. Moreover, these values appears to be


Fig. 6. Dubinin-Radushkevich isotherm plots of of $\mathrm{Sr}^{2+}$ sorbed by (a) kaolinite, and (b) by clinoptilolite. ㅁ: $298 \mathrm{~K}$, ๑: $333 \mathrm{~K}$.

smaller than the ones reported earlier for $\mathrm{Cs}^{+}$sorption on both minerals under the same experimental conditions [1]. As was mentioned in the experimental part, the solutions were prepared using tapwater which contained high concentration of $\mathrm{Ca}(200 \mathrm{mg} / \mathrm{L})$. The reason for the inhibition of $\mathrm{Sr}^{2+}$ sorption is plausibly caused by the competition of the $\mathrm{Ca}^{2+}$ ions with $\mathrm{Sr}^{2+}$ ions for the sorption sites, as both ions possess close hydrated radius $(\sim 4.12 \AA)$ [18]. The competition by $\mathrm{Ca}^{2+}$ ions was reported to greatly decrease the distribution coefficients and selectivity of $\mathrm{Sr}^{2+}$ on clinoptilolite and other types of exchangers [19].

The energy of sorption, $E$, was calculated using the D-R constant $K$ according to the relation $E=(-2 K)^{-1 / 2}$. The calculated $E$ values are given in Table 3 . The values are much below those corresponding to inner sphere complex formation (chemical complexation). This is in line with the
Table 3. D-R parameters, $k, C_{\mathrm{m}}$, and $E$, obtained from the plots $\mathrm{Sr}^{2+}$ uptake by kaolinite and clinoptilolite at $25^{\circ} \mathrm{C}$ and $60^{\circ} \mathrm{C}$.

\begin{tabular}{lccccc}
\hline Sample & Temperature & \multicolumn{3}{c}{ D-R constants } & \multirow{2}{*}{$R$} \\
\cline { 3 - 5 } & $\left({ }^{\circ} \mathrm{C}\right)$ & $K$ & $\begin{array}{c}C_{\mathrm{m}} \\
(\mathrm{meq} / 100 \mathrm{~g})\end{array}$ & $\begin{array}{c}E \\
(\mathrm{~kJ} / \mathrm{mol})\end{array}$ & \\
\hline Sr-kaolinite & 25 & 0.0059 & 0.12 & 9.2 & 0.9289 \\
& 60 & 0.0053 & 0.24 & 9.7 & 0.8429 \\
\hline Sr-clinoptilolite & 25 & 0,0046 & 0.40 & 10.4 & 0.9337 \\
& 60 & 0.0041 & 0.68 & 11.0 & 0.9615 \\
\hline
\end{tabular}


earlier results suggesting that $\mathrm{Sr}^{2+}$ has never been shown to form inner sphere complexes on any hydrated mineral surfaces [11].

\section{III - Thermodynamic parameters}

The thermodynamic parameters, $\Delta H^{\circ}, \Delta S^{\circ}$, and $\Delta G^{\circ}$ of sorption are useful in defining whether the sorption reaction is endothermic or exothermic, the stability of the system undergoing sorption, and the spontaneity of the sorption process. These parameters can be calculated using the following equations:

$$
\begin{aligned}
& \Delta G^{\circ}=-R T \ln R_{\mathrm{d}}, \\
& \Delta H^{\circ}=R \ln \frac{R_{\mathrm{d}}\left(T_{2}\right)}{R_{\mathrm{d}}\left(T_{1}\right)}\left(\frac{T_{1} T_{2}}{T_{2}-T_{1}}\right), \\
& \Delta S^{\circ}=\frac{\Delta H^{\circ}-\Delta G^{\circ}}{T} .
\end{aligned}
$$

The distribution ratio, $R_{\mathrm{d}}(\mathrm{mL} / \mathrm{g})$, in the above equations is an empirical equilibrium constant that is valid at a particular initial concentration and reaction conditions. The $R_{\mathrm{d}}$ value is calculated from the ratio of the equilibrium concentration of the sorbate on the solid to its concentration in the liquid. The values of $\Delta H^{\circ}, \Delta S^{\circ}$, and $\Delta G^{\circ}$ of sorption obtained for $\mathrm{Sr}^{2+}$ uptake on kaolinite and clinoptilolite are summarized in Table 4. The negative standard Gibbs energy changes indicate that sorption is a spontaneous process in all cases, and the magnitudes of $\Delta G^{\circ}$ are much below the typical values of chemisorption, the thing implying that weak electrostatic (ion-exchange) type forces and outer sphere complex formation dominate the sorption mechanisms.

Positive $\Delta H^{\circ}$ values were obtained for $\mathrm{Sr}^{2+}$ sorption on kaolinite and clinoptilolite indicating that the uptake processes are endothermic, i.e, the uptake of this ion increases with temperature increase. This behavior differs from the one reported for $\mathrm{Cs}^{+}$in our earlier study, which showed exothermic behavior [1]. The difference can probably be attributed to the large difference in hydration enthalpies, being -276 and $-1443 \mathrm{~kJ} / \mathrm{mol}$ for $\mathrm{Cs}^{+}$and $\mathrm{Sr}^{2+}$ ions, respectively. Metal ions with high hydration energies are well solvated in water. For these cations to be able to travel through solution and reach the sorption sites, it is necessary for them first to be stripped out (at least partially) of their hydration shell, a process that requires energy input. If this dehydration energy exceeds the exothermicity associated with the sorption of a metal ion on a solid surface, then the overall energy balance will lead to an endothermic behavior. Here, it is implicitly assumed that, upon sorption, the environment of the

Table 4. Values of $\Delta H^{\circ}, \Delta S^{\circ}$, and $\Delta G^{\circ}$ calculated from the sorption data of $\mathrm{Sr}^{2+}$ on kaolinite and clinoptilolite.

\begin{tabular}{lcccc}
\hline \multirow{2}{*}{ Sample } & $\Delta H^{\circ}(\mathrm{kJ} / \mathrm{mol})$ & $\Delta S^{\circ}(\mathrm{J} / \mathrm{mol} \mathrm{K})$ & \multicolumn{2}{c}{$\Delta G^{\circ}(\mathrm{kJ} / \mathrm{mol})$} \\
\cline { 4 - 5 } & & & $298 \mathrm{~K}$ & $333 \mathrm{~K}$ \\
\hline Sr-kaolinite & 11.3 & 63.5 & -8.1 & -9.3 \\
Sr-clinoptilolite & 9.8 & 78.5 & -13.6 & -16.3 \\
\hline
\end{tabular}

metal ions becomes 'less aqueous' than it was in the solution state. This assumption is supported by earlier EXAFS examinations which showed that, at low initial $\mathrm{Sr}^{2+}$ concentrations, this ion is sorbed as a partially aquated species onto octahedral sites on the kaolinite surface [9]. Consequently, since the hydration energy of $\mathrm{Sr}^{2+}$ largely exceeds that of $\mathrm{Cs}^{+}$, the mobility of $\mathrm{Sr}^{2+}$ in solution is more hindered compared to that of $\mathrm{Cs}^{+}$. Thus increasing this mobility will require enhancing the dehydration steps, the thing achieved by increasing the temperature. The endothermic behavior of $\mathrm{Sr}^{2+}$ on clinoptilolite was also reported earlier in another study [18]. In that study, however, the authors suggested that the increase in temperature leads to an increase in the hydrated radii of divalent cations due to the expansion in the water molecules present in the hydration sphere, an argument that can hardly explain the increased uptake of $\mathrm{Sr}^{2+}$ at higher temperatures.

In all cases, positive standard entropy changes are observed, as seen from Table 4. These values correspond to entropy changes in the system and must be distinguished from the total entropy change that takes into account the entropy change of the surroundings as well. The positive values of entropy change indicates that more mobility is generated with in the system as a result of the sorption process. Normally, one might expect that the entropy change of the system be negative as a result of a sorption reaction, since such reaction leads to transferring the sorbate ions from a disordered state in the solution to a more ordered state when fixed by the sorbent. However, two other factors might outweigh this decrease in the disorder. One of them could be referred to the dehydration steps that increase the mobility of the ions and that of the surrounding water molecules within the body of the solution. Another reason might stem from the larger number of specie leaving the sorbent when a sorbate is exchanged for them, in particular if the charge of that sorbate exceeds those of the ones exchanged out of the sorbent matrix, e.g. two monovalent ions exchanged for one divalent ion. Both of the above factors might contribute to the generation of more entropy upon sorption of $\mathrm{Sr}^{2+}$ on both minerals.

\section{IV - Desorption studies}

In order to check the sorption stability of $\mathrm{Sr}^{2+}$ ions fixed by kaolinite and clinoptilolite, desorption experiments were performed. These experiment do not reflect the reversibility of sorption in its strict thermodynamic sense but it can provide an indication about the stability of initially sorbed ions on their fixation sites. In these experiments, $0.1 \mathrm{~g}$ of solid samples prepared initially by sorption experiments with initial concentrations of $\mathrm{Sr}\left(\mathrm{NO}_{3}\right)_{2}$ of $10 \mathrm{mg} / \mathrm{L}$ and $50 \mathrm{mg} / \mathrm{L}$, were contacted with $10 \mathrm{~mL}$ tapwater and shaken for periods ranging from 10 minutes up to 7 days at controlled temperatures of $250{ }^{\circ} \mathrm{C}$ and $600^{\circ} \mathrm{C}$. At the end of shaking period, the concentration of the released $\mathrm{Sr}$ was measured using AAS and the desorption percentages were calculated. According to the results, at the end of one weak period, the percentage desorption of $\mathrm{Sr}^{2+}$ from the initially Sr-loaded minerals did not exceed $6 \%$ and $10 \%$ in the clinoptilolite and kaolinite cases, respectively. As expected, more $\mathrm{Sr}^{2+}$ desorbed from the samples prepared at higher initial concentration, 
but throughout these experiments, the effect of temperature was not clear and more experiments using a wide range of concentrations are required to get reliable results. The same experiments were also performed for Cs-sorbed minerals. According to the results, while the desorption of $\mathrm{Cs}^{+}$ from clinoptilolite was slightly larger than that of $\mathrm{Sr}^{2+}$, much higher desorption (about 40\%) was observed in the case of kaolinite.

\section{V - SEM/EDS characterization of the Sr-sorbed minerals}

Kaolinite and clinoptilolite samples were analyzed using XRPD and SEM/EDS prior to and following loading with $\mathrm{Sr}^{2+}$ ions. Loading of $\mathrm{Sr}$ was performed by reacting $50 \mathrm{~mL}$ aliquots of $500 \mathrm{mg} / \mathrm{L}$ solution of $\mathrm{Sr}\left(\mathrm{NO}_{3}\right)_{2}$ with $0.50 \mathrm{~g}$ of kaolinite or clinoptilolite for 48 hours at $25^{\circ} \mathrm{C}$. SEM/EDS analysis was performed to detect any morphological changes and to elucidate the distribution of the two ions on the surface of kaolinite. According to the SEM analysis, no observable change took place in the morphology of kaolinite and clinoptilolite particles upon sorption. The EDS characterization was performed in two modes; one as spot analysis of a total of ten points selected randomly on the surface, and the other by recording x-ray maps of elements that constitutes the mineral surfaces. The results of the spot analysis were averaged and provided in Table 5 for kaolinite and clinoptilolite, respectively. The maps of $\mathrm{Sr}^{2+}$ are also compared with those of $\mathrm{Al}$ and $\mathrm{Si}$, the major structural elements in kaolinite, as demonstrated in Figs. 7a,b. The numbers should be viewed with care due to the high error that can be associated with EDS measurement, in particular for quantities below 5-10 percent. The standard deviation values provided with the numbers were based on deviation of the arithmetic mean for 10 data points.

XRPD was used to check for any changes in kaolinite and clinoptilolite structures upon sorption of $\mathrm{Sr}^{2+}$ ions. The patterns indicated no significant change in the peak positions, peak intensities, or FWHM of the peaks corresponding to
Table 5. EDS findings of the atomic percentages of $\mathrm{Al}, \mathrm{Si}, \mathrm{O}, \mathrm{Na}, \mathrm{K}$, $\mathrm{Mg}, \mathrm{Ca}$, and $\mathrm{Sr}$ in kaolinite and clinoptilolite minerals.

\begin{tabular}{lrrrr}
\hline \multirow{2}{*}{ Element } & \multicolumn{4}{c}{ Atomic percentage } \\
\cline { 2 - 5 } & Kaolinite & Sr-kaolinite & Clinoptilolite & Sr-clinoptilolite \\
\hline $\mathrm{O}$ & $66.84 \pm 0.80$ & $65.08 \pm 2.77$ & $61.94 \pm 0.70$ & $62.37 \pm 1.32$ \\
$\mathrm{Na}$ & $0.47 \pm 0.04$ & $0.48 \pm 0.12$ & $0.56 \pm 0.12$ & $0.74 \pm 0.14$ \\
$\mathrm{Mg}$ & $0.34 \pm 0.05$ & $0.33 \pm 0.05$ & $0.86 \pm 0.13$ & $0.88 \pm 0.12$ \\
$\mathrm{Al}$ & $14.09 \pm 1.95$ & $11.64 \pm 1.75$ & $5.30 \pm 0.02$ & $5.11 \pm 0.15$ \\
$\mathrm{Si}$ & $17.61 \pm 0.66$ & $16.16 \pm 3.53$ & $23.73 \pm 0.89$ & $23.38 \pm 0.96$ \\
$\mathrm{~K}$ & $0.14 \pm 0.12$ & $0.12 \pm 0.07$ & $1.61 \pm 0.12$ & $0.87 \pm 0.13$ \\
$\mathrm{Ca}$ & $0.50 \pm 0.21$ & $0.44 \pm 0.27$ & $1.05 \pm 0.11$ & $1.27 \pm 0.17$ \\
$\mathrm{Sr}$ & $0.00 \pm 0.00$ & $0.92 \pm 0.26$ & $0.00 \pm 0.00$ & $1.47 \pm 0.23$ \\
\hline
\end{tabular}

basic reflections of both minerals, indicating the structural stability of these minerals under the prevailing experimental conditions.

\section{Conclusions}

In light of the findings of this work, the following main conclusions can be stressed:

- The sorption capacity of clinoptilolite mineral towards $\mathrm{Sr}^{2+}$ is higher than that of kaolinite. Under our experimental conditions, the structure of both minerals seems to be preserved.

- Pseudo second order rate kinetics provided good description of the sorption data, and the obtained apparent rate constants indicated faster sorption on kaolinite accompanied by a lower activation energy of sorption on this mineral as compared with clinoptilolite.

- Unlike the case of kaolinite, the earlier stages of $\mathrm{Sr}^{2+}$ sorption by clinoptilolite appeared to be affected by intraparticle diffusion.

- The uptake of $\mathrm{Sr}^{2+}$ ions on both minerals was more adequately described by Freundlich and Dubinin-Radushkevich isotherm models, but the sorption capacity was


b)
Fig. 7. EDS mapping of $\mathrm{Al}, \mathrm{Si}$, and $\mathrm{Sr}$ on: (a) kaolinite, and (b) clinoptilolite minerals. 
small as a result of the plausible competition by $\mathrm{Ca}^{2+}$ ions present in the sorption medium.

- Sorption of $\mathrm{Sr}^{2+}$ on both minerals was spontaneous and endothermic with energy values corresponding to possibly electrostatic type of interactions (ion exchange) and outersphere complex formation.

Acknowledgment. This work was sponsored by the 2003 IYTE 04 fund provided by Izmir Institute of Technology. The authors would like to thank Mr. Sinan Yilmaz for his help in the AAS measurements, and the Center of Material Research/Izmir Institute of Technology for their assistance in the SEM/EDS and XRPD measurements.

\section{References}

1. Shahwan, T., Akar, D., Eroglu, A. E.: Physicochemical characterization of the retardation of aqueous $\underline{C s}^{ \pm}$ions by natural kaolinite and clinoptilolite minerals. J. Colloid Interf. Sci. 285, 9 (2005).

2. Friedlander, G., Kennedy, J. W., Macias, E. S., Miller, J. M.: Nuclear and Radiochemistry. Wiley \& Sons, New York (1984).

3. Chorover, J., Choi, S., Amistadi, M. K., Karthikeyan, K. G., Crosson, G., Mueller, K. T.: Linking cesium and strontium uptake to kaolinite weathering in simulated tank waste leachate. Environ. Sci. Technol. 37, 2200 (2003).

4. Jeong, C. H.: Mineralogical and hydrochemical effects on adsorption removal of cesium-137 and strontium-90 by kaolinite. J. Environ. Sci. Health A 36, 1089 (2001).

5. Samadfam, M., Jintoku, T., Sato, S., Ohashi, H.: Effect of humic acid on the sorption of $\underline{\operatorname{Sr}(I I)}$ on kaolinite. J. Nucl. Sci. Technol. $\overline{37}, 180 \overline{(2000) \text {. }}$

6. Takahashi, Y., Minai, Y., Ambe, S., Makide, Y., Ambe, F.: Comparison of adsorption behavior of multiple inorganic ions on kaolinite and silica in the presence of humic acid using the multitracer technique. Geochim. Cosmochim. Acta 63, 815 (1999).

7. Hakem, N., Apps, J. A., Moridis, G. J., Al Mahamid, I.: Sorption of fission product radionuclides, Cs-137 and Sr-90, by Savannah River Site sediments impregnated with colloidal silica. Radiochim. Acta 92, 419 (2004).
8. Sahai, N., Carroll, S. A., Roberts, S., O'Day, P. A.: X-ray absorption spectroscopy of strontium(II) coordination - II. Sorption and precipitation at kaolinite, amorphous silica, and goethite surfaces. J. Colloid Interf. Sci. 222, 198 (2000).

9. Parkman, R. H., Charnock, J. M., Livens, F. R., Vaughan, D. J.: A study of the interaction of strontium ions in aqueous solution with the surfaces of calcite and kaolinite. Geochim. Cosmochim. $\overline{\text { Acta }} \mathbf{6 2}, \overline{1481} \overline{1}(1998)$.

10. Chen, C. C., Hayes, K. F.: X-ray absorption spectroscopy investigation of aqueous $\mathrm{Co}$ (II) and $\underline{\mathrm{S}} \mathrm{r}(\mathrm{II})$ sorption at clay-water interfaces. Geochim. Cosmochim. Ácta 63, 3205 (1999).

11. Um, W., Papelis, C.: Metal ion sorption and desorption on zeolitized tuffs from the Nevada Test Site. Environ. Sci. Technol. 38, $\overline{496}(200 \overline{4})$.

12. Elizondo, N. V., Ballesteros, E., Kharisov, B. I.: Cleaning of liquid radioactive wastes using natural zeolites. Appl. Radiat. Isotop. 52, $27(2000)$.

13. Ye, M. L., Lu, S. J., Quin, C. K., Xu, L. H., He, A., Tang, Z. H., Xu, G. Q., Fan, X. L., Gu, J. F., Du, Z. C.: Investigation of sorption and migration of $\mathrm{Sr}-90$ on clinoptilolite and mordenite. Radiochim. Acta 81, 103 (1998).

14. Valcke, E., Engels, B., Cremers, A.: The use of zeolites as amendments in radiocaesium- and radiostrontium-contaminated soils: A soil-chemical approach. 2. Sr-Ca exchange in clinoptilolite, mordenite, and zeolite A. Zeolites 18, 212 (1997).

15. Rajec, P., Macasek, F., Feder, M., Misaelides, P., Samajova, E.: Sorption of caesium and strontium on clinoptilolite- and mordenite-containing sedimentary rocks. J. Radioanal. Nucl. Chem. 229, 49 (1998).

16. Ho, Y. S., Mckay, G.: The kinetics of sorption of divalent metal ions onto sphagnum moss peat. Water Res. 34, 736 (2000).

17. Kannan, N., Sundaram, M. M.: Kinetics and mechanism of removal of methylene blue by adsorption on various carbons a comparative study. Dyes Pigments 51, 27 (2001).

18. Palmer, J. L., Gunter, M. E.: The effects of time, temperature, and concentration on $\mathrm{Sr}^{2+}$ exchange in clinoptilolite in aqueous solutions. Am. Mineral. 86, 431 (2001).

19. Marinin, D. V., Brown, G. N.: Studies of sorbent/ion-exchange materials for the removal of radioactive strontium from liquid radioactive waste and high hardness groundwaters. Waste Manage. 20, 545 (2000). 